\title{
Photocontrols of Alkali Metal Salt Permeation with 1-Octadecyl- 3,3-dimethyl-6'-nitrospiro(indoline-2,2'-2H-benzopyran)- Blended Membrane
}

\author{
Takeo SHIMIDZU* and Masakazu YoshiKAwA \\ Department of Hydrocarbon Chemistry, Faculty of Engineering, \\ Kyoto University, Kyoto 606, Japan \\ (Received February 25, 1983)
}

\begin{abstract}
Blended membranes were obtained by the introduction of 1-octadecyl-3,3dimethyl-6'-nitrospiro(indoline-2,2'-2H-benzopyran) into poly(2-hydroxyethyl methacrylate-coacrylonitrile) and cellulose acetate membranes. The salt permeation rates through these membranes were controlled by Xe lamp illumination.
\end{abstract}

KEY WORDS Photocontrolling Salt Permeation / Spiropyran Compound /

Blended Membrane / Photochromism /

To develop a photocontrollable carrier, a novel spiropyran compound with a long alkyl group, 1octadecyl-3,3-dimethyl- 6'-nitrospiro(indoline- 2,2'$2 \mathrm{H}$-benzopyran) (1) was synthesized. ${ }^{1}$ The ability of 1 as a salt transporting carrier was studied using a liquid membrane. It has been found that the concentration (active transport) of salts can be achieved with an anisotropic membrane and illumination. ${ }^{1}$ The introduction of a spiropyran compound with a long alkyl group, $\mathbf{1}$, into a synthetic polymer membrane will render possible the photocontrol of membrane properties.

To date, the conversion of light energy into mechanical ${ }^{2}$ and into electrical energy, ${ }^{3}$ and the photocontrol of chemical functions such as enzyme activity $^{4}$ have been investigated to determine the application of spiropyran compounds to membranes. In the present paper, in order to develop means for the photocontrol of salt permeation membranes, poly(2-hydroxyethyl methacrylate-coacrylonitrile), poly(2-co-3), and cellulose acetate (4) membranes containing 1-octadecyl-3,3-dimethyl$6^{\prime}$-nitrospiro(indoline-2,2'-2 $H$-benzopyran) (1) were studied. These blended membranes controlled salt flux when used with Xe lamp illumination.

\section{EXPERIMENTAL}

\section{Materials}

A novel spiropyran compound with a long alkyl group, 1-octadecyl-3,3-dimethyl-6'-nitrospiro(indoline-2,2'-2H-benzopyran) (1), was synthesized as previously described. ${ }^{1}$ 2-Hydroxyethyl methacrylate (2), acrylonitrile (3), 2,2'-azobisisobutyronitrile (AIBN), N,N-dimethylformamide (DMF), and acetone were purified in the usual manner. Cellulose acetate (4), acetyl content $55 \%$, was purchased from Wako Pure Chemical Industries, Ltd. and used without further purification.

Poly(2-hydroxyethyl methacrylate-co-acrylonitrile), poly(2-co-3), was prepared by the usual radical copolymerization of 2 and 3 initiated by AIBN. The results of the copolymerization are shown in Table I.

Preparation of the Blended Membrane, 1+Poly(2co-3)

A casting solution was prepared as follows: $100 \mathrm{mg}$ of 1 was dissolved in $10.0 \mathrm{~cm}^{3}$ of a DMF solution containing $2.5 \mathrm{~g}$ of poly $\left(2-\mathrm{co}^{-3}\right)$. The solution was poured onto a glass plate with an applicator and the solvent was allowed to evaporate at $40^{\circ} \mathrm{C}$ (relative humidity, $70.0 \%$ ) for $2 \mathrm{~h}$. The thickness of the membrane was $c a .40 \mu \mathrm{m}$. 
Table I. Results of the copolymerization of 2-hydroxyethyl methacrylate (2) and acrylonitrile $(3)^{a}$

\begin{tabular}{|c|c|c|c|c|c|}
\hline \multirow{4}{*}{$\begin{array}{l}\text { Exp. } \\
\text { No. }\end{array}$} & \multicolumn{2}{|c|}{ Monomer } & \multirow{4}{*}{$\frac{\mathrm{AIBN}}{\mathrm{mg}}$} & \multirow{2}{*}{\multicolumn{2}{|c|}{ Mol fraction of 2 in }} \\
\hline & \multirow{3}{*}{$\frac{2}{\mathrm{~cm}^{3}}$} & \multirow{3}{*}{$\frac{3}{\mathrm{~cm}^{3}}$} & & & \\
\hline & & & & Monomer & Polymer \\
\hline & & & & & \\
\hline 1 & 3.5 & 6.5 & 104.8 & 0.226 & 0.218 \\
\hline 2 & 4.5 & 5.5 & 98.0 & 0.300 & 0.317 \\
\hline 3 & 4.8 & 5.2 & 96.2 & 0.326 & 0.369 \\
\hline
\end{tabular}

a Polymerizations were carried out in $40 \mathrm{~cm}^{3}$ DMF for 4 days at $50^{\circ} \mathrm{C}$.

\section{Preparation of the Blended Membrane, $1+4$}

A casting solution was prepared by dissolving $20-120 \mathrm{mg}$ of 1 and $1.2 \mathrm{~g}$ of 4 in $10.0 \mathrm{~cm}^{3}$ acetone. The solution was poured onto a glass plate with an applicator and the solvent was allowed to evaporate at an ambient temperature. The thickness of the membrane was $30-40 \mu \mathrm{m}$.

\section{Spectroscopic Measurement}

Absorption spectra were measured with a Union Giken SM-302 spectrophotometer.

\section{Illumination}

Illumination (Visible and UV illumination) was carried out with a $500 \mathrm{~W}$ Xenon lamp.

\section{Salt Permeation}

A cell consisting of two chambers was used to study salt permeation. A sketch of the cell is shown in Figure 1. A membrane $3.14 \mathrm{~cm}^{2}$ in area was placed tightly with Parafilm between the chambers of the cell. Permeation of salts in the $\mathrm{KCl}-\mathrm{NaCl}$ binary system was studied as follows: $15.0 \mathrm{~cm}^{3}$ of a solution containing $0.5 \mathrm{~mol} \mathrm{dm}^{-3}$ of $\mathrm{KCl}$ and $\mathrm{NaCl}$ was placed on one side, and $15.0 \mathrm{~cm}^{3}$ of distilled water on the other side. The membrane was illuminated from a quartz window.

Salt concentrations were measured with a Jarrel Ash AA8200 atomic absorption spectrophotometer.

\section{RESULTS AND DISCUSSION}

\section{Photochromism of $\mathbf{1}$ in the Blended Membrane}

1 in the blended membranes, $1+\operatorname{poly}(2-c o-3)$ and $1+4$, was observed to ring-open by Xe lamp illumi-

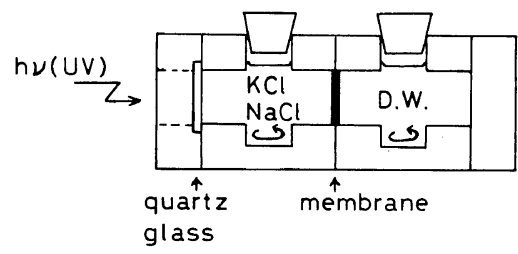

Figure 1. Rough sketch of the cell. Volume, $15 \mathrm{~cm}^{3}$; effective membrane area, $3.14 \mathrm{~cm}^{2} ;[\mathrm{KCl}]_{0}=[\mathrm{NaCl}]_{0}=$ $0.5 \mathrm{~mol} \mathrm{dm}^{-3}$

nation and ring-close by Vis illumination reversibly even when the present synthetic polymer membrane was used as well as in the organic solvents reported previously. ${ }^{1}$ The photochromic process is presented as follows.

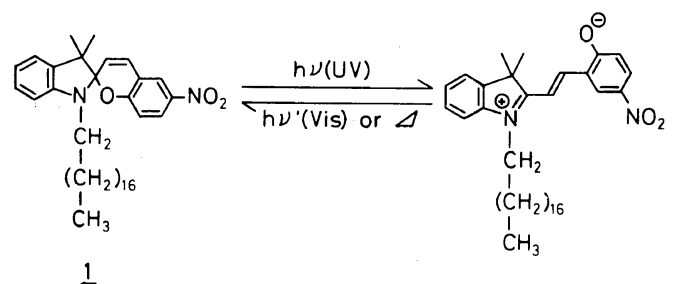

Scheme 1

The absorption maximum wavelength of the chromophore formed by the ring-opening of $\mathbf{1}$ in the $1+$ poly $(2-c o-3)-$ blended membrane in the visible range was observed at $550 \mathrm{~nm}$ regardless of the chemical composition of poly(2-co-3). On the other hand, the content of $\mathbf{1}$ affected the absorption maximum of the chromophore. The maximum of 1 in the 1+4-blended membrane shifted to a shorter wavelength with an increase in the content of 1 as shown in Table II. Dimroth's solvent polarity value $\left(E_{\mathrm{T}}\left(25^{\circ} \mathrm{C}\right)\right)$ of the $\mathbf{1}+\mathbf{4}$-blended membrane was evaluated from the relationship between $\lambda_{\text {max }}^{\mathrm{Vis}}$ and $E_{\mathrm{T}}\left(25^{\circ} \mathrm{C}\right){ }^{1} E_{\mathrm{T}}\left(25^{\circ} \mathrm{C}\right)$ values of the $1+4$-blended membrane are shown in Table II. The polarity of the 1+4-blended membrane increased with the content of 1 suggesting that the increase in the amount of the opened-carrier come about as a result of both the increase in the content of 1 and Xe lamp illumination which caused the ionicity of the membrane to increase on account of increased charges. Thus, the polarity of the membrane increased.

Salt Permeation through the Blended Membrane, 1+Poly (2-co-3)

During the salt permeation experiment under $\mathrm{Xe}$ 
Table II. $\quad \lambda_{\max }^{\mathrm{Vis}}$ and Dimroth's solvent polarity values of the blended membrane, $1+4$

\begin{tabular}{|c|c|c|}
\hline 1 & $\lambda \lambda_{\max }^{V i s}$ & $E_{\mathrm{T}}\left(25^{\circ} \mathrm{C}\right)$ \\
\hline $\mathrm{mg} 1.2 \mathrm{~g}^{-1}$ of 4 & $\mathrm{~nm}$ & $\mathrm{kcal} \mathrm{mol}^{-1}$ \\
\hline 20 & 560 & 47.7 \\
\hline 40 & 553 & 50.3 \\
\hline 60 & 550 & 51.5 \\
\hline 80 & 547 & 52.6 \\
\hline 120 & 545 & 53.3 \\
\hline
\end{tabular}

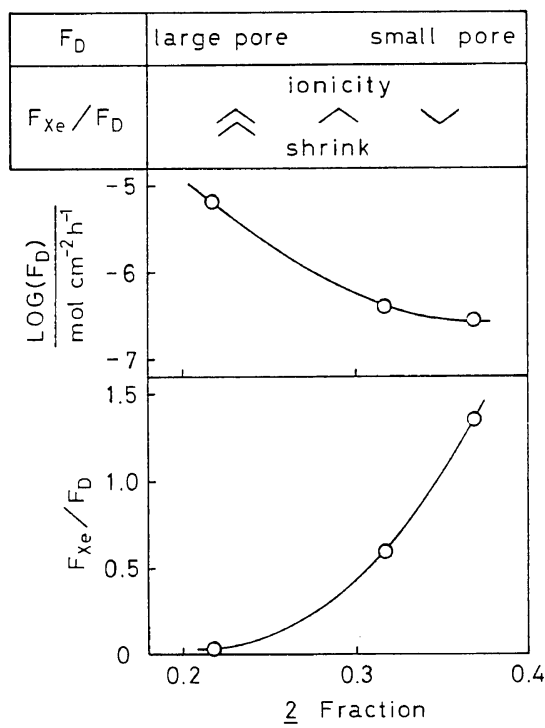

Figure 2. Relationship between $F_{\mathrm{D}}$ and $F_{\mathrm{Xe}} / F_{\mathrm{D}}$, and mol fraction of $\mathbf{2}$ in the $\mathbf{1}+\operatorname{poly}(\mathbf{2}-\mathrm{co}-3)$-blended membrane. $1,100 \mathrm{mg}$; poly(2-co-3), $2.5 \mathrm{~g}$.

lamp illumination, the coloration of the membrane due to the ring-opening of $\mathbf{1}$ became pale. Following this, the salt flux in the dark, $F_{\mathrm{D}}$, and that under Xe lamp illumination, $F_{\mathrm{Xe}}$, were discussed at the initial stage in order to eliminate the fatigue effect on salt flux during the Xe lamp illumination on $\mathbf{1}$.

In Figure 2, the salt flux in the dark and the ratio of the flux under Xe lamp illumination to that in the dark through the $1+$ poly(2-co-3)-blended membrane are plotted against the fraction of $\mathbf{2}$ in poly(2$c o-3)$. The salt flux in the dark decreased with increase in the fraction of 2 . This implies that the size of pores where salt permeates became small.

Before considering the flux ratio, the following two matters should be taken into account: (A)
Illumination of the membrane with a Xe lamp causes 1 to open and the membrane to take on a more ionic character. Consequently, the membrane becomes hydrophilic and salts permeate readily. (B) Structural change accompanying the ring-opening of 1 causes the membrane to shrink as Smets reported, ${ }^{2}$ and narrows the pores through which the salts permeate. Consequently, salt permeation is suppressed, contrary to the consideration (A).

In the case of the membrane with a low fraction of 2 , the decrease in flux is considered to be caused by a reduction in the pore size on Xe lamp illumination. While this is taking place, the flux ratio, $F_{\mathrm{Xe}} / F_{\mathrm{D}}$, increases with the fraction of 2 , possibly because of the increase in the ionic effect due to the ring-opening of 1 with an increase in the fraction of 2 in poly (2-co-3). It is considered that the membrane with the high fraction of $\mathbf{2}$ has small pores but which are not reduced by the ring-opening of 1 , since the membrane with the high fraction of $\mathbf{2}$ forms more hydrogels when the membrane is illuminated with the Xe lamp. Therefore the membrane with the high fraction of $\mathbf{2}$ is not very much affected by the contracting factor during the Xe lamp illumination period. This membrane is considered to become both hydrophilic and ionic. Therefore, the membrane with the high fraction of $\mathbf{2}$ gives high flux on Xe lamp illumination.

\section{Salt Permeation through the Blended Membrane, $1+4$}

In Figure 3, the salt flux in the dark, the ratio of the flux under Xe lamp illumination to that in the dark, and the selectivity of permeation of $\mathrm{K}^{+}$and $\mathrm{Na}^{+}$are plotted against the weight of 1 in the blended membrane $1+4$ where 4 is $1.2 \mathrm{~g}$.

From the flux in the dark, the pore size is considered to change abruptly at a content of 1 in the vicinity of 60 to $80 \mathrm{mg}$.

A steep rise in the flux ratio, $F_{\mathrm{Xe}} / F_{\mathrm{D}}$, was observed at a low content of 1 , up to $40 \mathrm{mg}$ implying that the ionic effect due to the ring-opening of $\mathbf{1}$ exceeds the contractile effect. This is also supported by the selectivity between $\mathrm{K}^{+}$and $\mathrm{Na}^{+}$under Xe lamp illumination. The fact that the selectivity, $\mathrm{K}^{+} / \mathrm{Na}^{+}$, falls to unity in Figure 3 indicates that the membrane becomes hydrophilic; that is, the membrane carries ionicity, since $\mathrm{K}^{+}$permeates more readily than $\mathrm{Na}^{+}$through the membrane with high hydrophobicity. The increased flux, $F_{\mathrm{Xe}}$, fell at a 


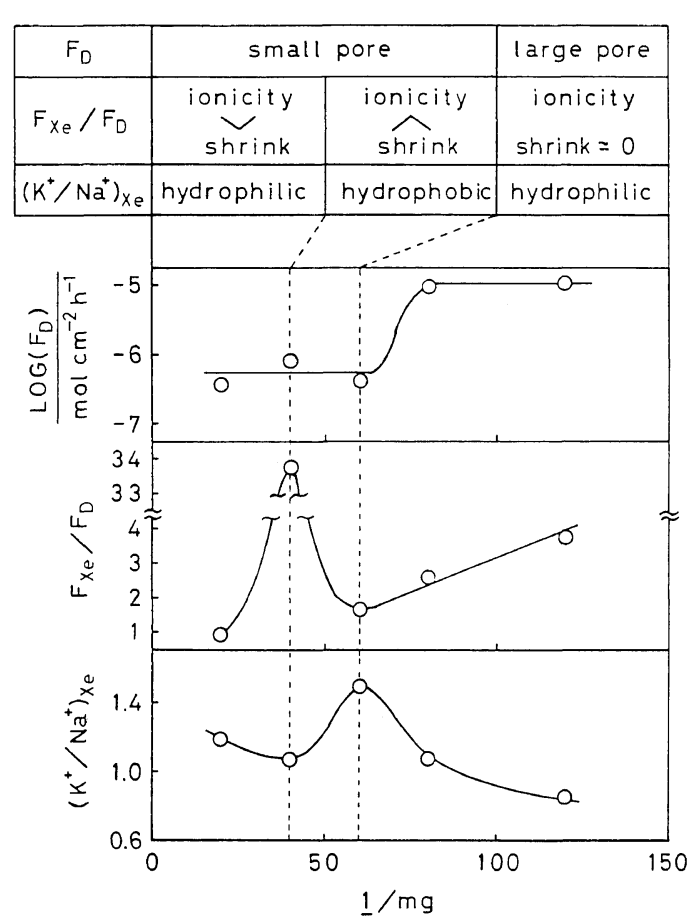

Figure 3. Relationship between $F_{\mathrm{D}}, F_{\mathrm{Xe}} / F_{\mathrm{D}}$, and selectivity $\left(\mathrm{K}^{+} / \mathrm{Na}^{+}\right)$and 1 content of the $1+4$-blended membrane. 4, $1.2 \mathrm{~g}$.

content of 1 from $40-60 \mathrm{mg}$. Apparently the membrane in this range shrinks and the polymer chains approach each other, the hydrophobicity of the membrane increases, and $\mathrm{K}^{+}$permeates selectively. In the range of a content of 1 over $60 \mathrm{mg}$, the contractile effect does not take precedence over the membrane property, since the pore size is too large. The salt flux under Xe lamp illumination increased owing to the increase in ionicity by the ring-opening of 1 , and the selectivity, $\mathrm{K}^{+} / \mathrm{Na}^{+}$, decreased. The membrane containing $120 \mathrm{mg}$ of $\mathbf{1}$, allowed more $\mathrm{Na}^{+}$than $\mathrm{K}^{+}$to permeates. Considering the fact that the constant of the complex formation of $\mathrm{NaCl}$ and the opened-carrier formed by Xe lamp illumination was four times higher than that of $\mathrm{KCl}$ and the opened-carrier, ${ }^{1}$ it may be assumed that the increase in the content of $\mathbf{1}$ caused the distance between the molecules of $\mathbf{1}$ to become shorter making it possible for the salts to permeate by a hopping mechanism, and as a result, $\mathrm{NaCl}$, with a high affinity toward the opened-carrier, permeated more readily than $\mathrm{KCl}$.

\section{CONCLUSIONS}

The photoresponsibility of the spiropyran influenced only by the physical structure of the membrane, that is, the spiropyran compound, interacted with the membrane matrix under the conditions of the experiment. But it is expected that the increase in the spiropyran content brings about the formation of channels in the blended membrane and the interaction between the spiropyran compound and salts leads to a rise in the flux and selectivity in permeation under Xe lamp illumination.

Acknowledgements. The authors are deeply grateful to the Instrumental.Analysis Research Center of Kyoto University for kindly granting permission to use its Jarrel Ash AA8200 atomic absorption spectrophotometer. This work was supported by a Grant-in-Aid from the Ministry of Education.

\section{REFERENCES}

1. T. Shimidzu and M. Yoshikawa, J. Membrane Sci., 13, 1 (1983).

2. G. Smets, Pure Appl. Chem., 30, 1 (1972).

3. S. Kato, M. Aizawa, and S. Suzuki, J. Membrane Sci., 1, 289 (1976).

4. I. Karube, Y. Nakamoto, and S. Suzuki, Biochim. Biophys. Acta, 445, 774 (1976). 